\title{
Fatalities due to Seasonal Variation in Tomato Genotypes
}

\author{
A.K. Singh ${ }^{1}$, R.P. Singh ${ }^{1}$, K. Singh ${ }^{2}$, M.K. Singh $^{3}$, \\ Avanish Kumar Singh ${ }^{3}$ and Umesh Singh $^{4}$ \\ ${ }^{1}$ Department of Botany, ${ }^{2}$ Department of Entomology, Udai Pratap \\ Autonomous College, Varanasi-221002 (U.P.), India \\ ${ }^{3}$ ICAR- Agricultural Technology Application Research Institute (ATARI), \\ Kanpur, 208002, (U.P.), India \\ ${ }^{4}$ Division of Crop Improvement, Indian Institute of Vegetable Research, PB- 01, PO-Jakhini \\ (Shahanshahpur), Varanasi- 221305 (U.P.), India \\ *Corresponding author
}

\begin{tabular}{|c|c|}
\hline & \\
\hline & \multirow{6}{*}{$\begin{array}{l}\text { Twenty three tomato genotypes were screened under field condition during two } \\
\text { consecutive seasons of spring-summer (February to May) and autumn-winter (October to } \\
\text { February). The differences in average day/night mean temperature/humidity of both the } \\
\text { season were } 15^{\circ} \mathrm{C} / 13.0^{\circ} \mathrm{C} \text { and } 46 \% / 39 \% \text {, respectively. Early flowering was observed in } \\
\text { summer compared to winter season and diminution of pollen viability is noticed in all the } \\
\text { genotypes during spring-summer whereas, in genotype Hisar lalit it was enhanced } 0.92 \\
\text { times. Fruit set percent at high temperature is stringently reliant on proper gametogenesis } \\
\text { (pollen and ovule development) and fertilization was markedly decreased in summer but } \\
\text { this reduction was only } 1.19 \text { times observed in Hisar Lalit (Sel-18) in comparison to } \\
\text { autumn-winter. The tomato plants in spring summer reveals stressed had significantly } 1.6- \\
2.5 \text { times higher chl a/b ratio compared to autumn-winter. Chl b was degraded faster at } \\
\text { high temperature than Chl a, represented by an increase in Chl a/b ratio with exposure. } \\
\text { High temperature increased titrable acidity of tomato fruit and it was enhanced } 1.30 \text { to } \\
1.03 \text { times during spring summer. Heat Susceptibility Index (HSI) was used to measure } \\
\text { stress tolerance in terms of minimizing the reduction in yield caused by unfavourable } \\
\text { versus favourable environments. The ideal genotypes perform better yield in all } \\
\text { environmental condition, therefore on the basis of HSI genotype PS-1(0.73), Hisar Lalit } \\
\text { (0.77), EC-538455 (0.80) showed better performance and can be used for breeding } \\
\text { purposes. }\end{array}$} \\
\hline Keywords & \\
\hline $\begin{array}{l}\mathrm{T} \\
\mathrm{su} \\
\mathrm{w} \\
\text { su }\end{array}$ & \\
\hline Articl & \\
\hline & \\
\hline & \\
\hline
\end{tabular}

\section{Introduction}

Abiotic stresses due to seasonal variations are often interrelated, either individually or in combination, they cause morphological, physiological, biochemical, and molecular changes that adversely affect plant growth and productivity, and ultimately yield. Heat stress induces severe cellular damage in plant species, including crop plants. Production of tomato (Solanum lycopersicum L.) in subtropical region of India is mainly confined to winter autumn-winter season, and radical decrease is observed summer. Thus, the production of tomato in these regions is mainly confined only to the winter season. 
Due to high price and demand of tomato in summer, the need for suitable variety in summer has long been demanded. There are many factors which are responsible for fruit setting and needed to be explored under high temperature stress. A number of vindications have been offered for the poor reproductive performance of tomatoes at high temperatures. These include reduced or abnormal pollen production, abnormal development of the female reproductive tissues, hormonal imbalances, low levels of carbohydrates, and lack of pollination (Abdalla and Verkerk, 1968; Peet et al., 1997). Dinar and Rudich (1985) reported that in tomato plants, high temperatures affect several physiological and biochemical processes dealing finally with yield reduction. Possible biochemical and/or physiological processes affected by temperature are photosynthetic enzyme activity; membrane integrity, photophosphorylation, and electron transport in chloroplast, stomatal conductance to $\mathrm{CO}_{2}$ diffusion and photo assimilate translocation.

Comparative performances of the genotypes under normal and high temperature conditions are also needed for better understanding of the reaction of individual component factor of pollen viability, fruit setting and yield attributing parameters aiming to select suitable heat tolerant genotypes. Therefore, considering the present need, the study was under taken to compare genotypic differences in respect of several fatalities due to high temperature in summer seasons compared to winter for selecting superior heat tolerant tomato genotypes suitable for both the seasons.

\section{Materials and Methods}

Twenty three tomato genotypes (eight indigenous and fifteen exotic collections) in two consecutive season's summer (February to May) and winter (October to February) were field evaluations. During crop duration differences in average day/night mean temperature/humidity of both the season were $15^{\circ} \mathrm{C} / 13.0^{\circ} \mathrm{C}$ and $46 \%$ / $39 \%$, respectively. Seeds were sown on second week of September for winter and first week of January for summer seasons. Twenty five days old seedlings after sowing were transplanted in the Research Farm of Udai Pratap Autonomous College, Varanasi during winter and after thirty days in summer. The experiment was laid out in Complete Randomized Block Design (CRBD) with three replications and ten plants of each genotype were evaluated under both the season. After sixty five day of temperature treatment in both seasons the observations were recorded on the different morphological and reproductive traits. Fruit set was expressed in percentage by counting the total number of flowers as well as total number of fruits per plant. For assessment of pollen viability flower buds were collected from 10 plants per genotype by removing pollens from the anthers using a needle. The pollen grains were touching on glass slide for determining the number of viable pollen grains through triphenyltetrazolium chloride (TTC) test as per Eti (1991). The chlorophyll was extracted in $80 \%$ acetone (Porra et al., 1989). The absorption of the extracts at wavelengths of $663,645 \mathrm{~nm}$ was recorded with a SP $722 \mathrm{E}$ spectrophotometer. The concentrations of chlorophyll a (Chl a) and chlorophyll b (Chl b) were calculated using the equations (Arnon, 1949) as follow and concentrations were expressed as $\mathrm{mg} \mathrm{g}^{-1}$ fresh weight. Chl a $=12.7 \mathrm{~A}_{663}-2.59 \mathrm{~A}_{645}, \mathrm{Chl} \mathrm{b}=22.9 \mathrm{~A}_{645}-$ $4.67 \mathrm{~A}_{663}$.

Heat Susceptibility Index (HSI) was used to measure stress tolerance in terms of minimizing the reduction in yield caused by unfavourable versus favourable environments. HSI was calculated for each genotype according to the formula of Fisher and Maurer (1978): 
$\mathrm{HSI}=\frac{1-\frac{Y}{Y p}}{1-\frac{X}{X p}}$

Where,

$\mathrm{Y}=$ mean tomato yield of a genotype under a stressed environment, $\mathrm{Yp}=$ mean yield of the same genotype under a stress-free environment, $\mathrm{X}=$ mean $\mathrm{Y}$ of all genotypes, $\mathrm{Xp}=$ mean $\mathrm{Yp}$ of all genotypes. In this experiment, stress implies high temperature, If HSI is $<0.5$, then the genotype is highly stress tolerant, if HIS $>0.5<1.0$, it is moderately stress tolerant, and if HIS $>1.0$, it is susceptible to stress. Graph of reduction in parameters were constructed using Microsoft Office Excel 2007.

\section{Results and Discussion}

Present experiment reveals that seasonal variations cause significant changes in flowering as well as yield attributes in tomato crop. Wide variation was observed among the genotypes in reflect of number of fruit set due to seasonal change. Marked decrease in fruit set percent in all the genotypes were observed during summer ranging from 1.19 times in Hisar Lalit (Sel-18) to 4.36 times in EC501577 (fig 1a).

Seasonal variation greatly influenced the viability of pollen grains in all the tomato genotypes and reduced greatly irrespective of genotypes during summer. Pressman et al., (2002) reported that the effect of high temperature on pollen viability was associated with carbohydrate metabolism during anther development. Under optimal temperature, soluble sugar concentration gradually increased in pollen. Continuous high temperature prevented the increase in starch concentration and lead to a decrease in soluble sugar in mature pollens and these possibly cause a decrease in pollen viability. Maximum viability of the pollen grains amongst the genotypes was observed during winter season but in contrary to that during summer increment of pollen viability in Hisar Lalit (Sel-18) (0.92 times), EC-538156 (1.0 times) 15-SB (1.0 times) was noted (fig 1b). Regarding total chlorophyll (chl $\mathrm{a}+\mathrm{b}$ ) reduction as well as enhancement both the trend was observed in summer, generally heat stress altered the chlorophyll and carotenoid content at high temperature in thermo-tolerant genotype.

In summer season the total chlorophyll (chl a + b) enhancement was observed maximum 1.13 times in EC-538441, while 0.88 times reduction was observed in EC-501577 (fig 1c) Heat treatment increased titrable acidity. Shellie and Mangan (1996) and Porat et al., (2000) reported that titrable acidity of grape fruit increased when heated with hot air or hot water. In present experiment also 1.30 to 1.03 times increased acidity was observed during summer season (fig 1d). The tomato plants in summer season reveals stressed had significantly 1.64-2.54 times higher chl a/b ratio compared to winter (fig 1e). Chl b was degraded faster at high temperature than $\mathrm{Chl}$ $\mathrm{a}$, represented by an increase in $\mathrm{Chl} \mathrm{a} / \mathrm{b}$ ratio with exposure. Similar finding on tomato under heat stress was also noticed by Camejo et al., (2005). HSI may be calculated separately in different stress environments to assess their stress potential. In this study, the HSI of yield in PS-1 (0.73), Hisar lalit (0.77), EC-538455 (0.80), EC-538156 (0.81), Kashi Amrit (089), 15-SB (0.90), EC-538441 (0.92) and EC-528372 (0.99) showed moderately tolerant while rest of the genotypes showed HSI more 1.0 (fig 1f). The importance of HSI in crop growing has been abridged by several researchers. 
Fig.1 Times fatalities in different parameters due to seasonal changes

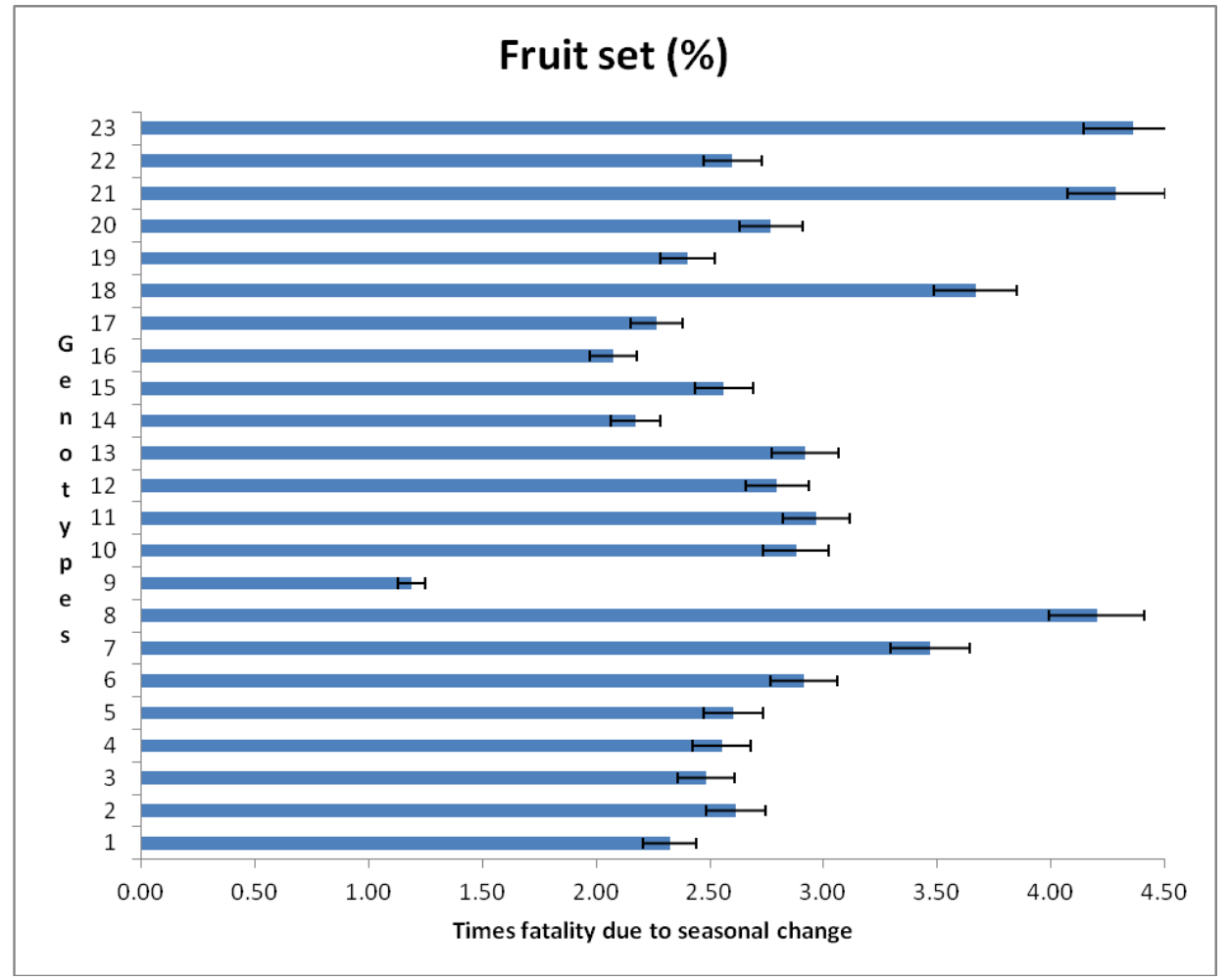

Fig.1a Fruit set $\%$ fatality due to seasonal changes

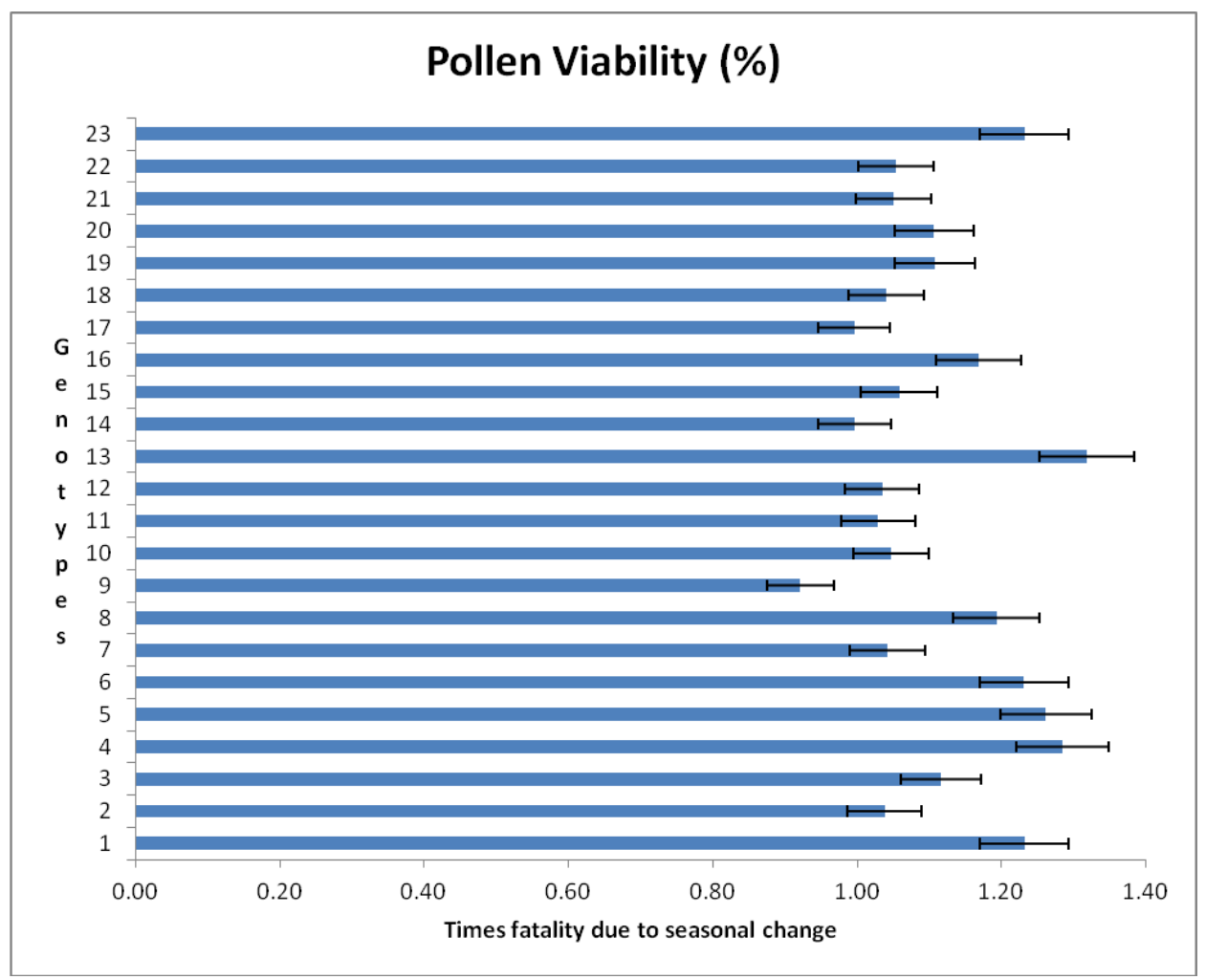


Fig.1b Pollen viability \% fatality due to seasonal changes

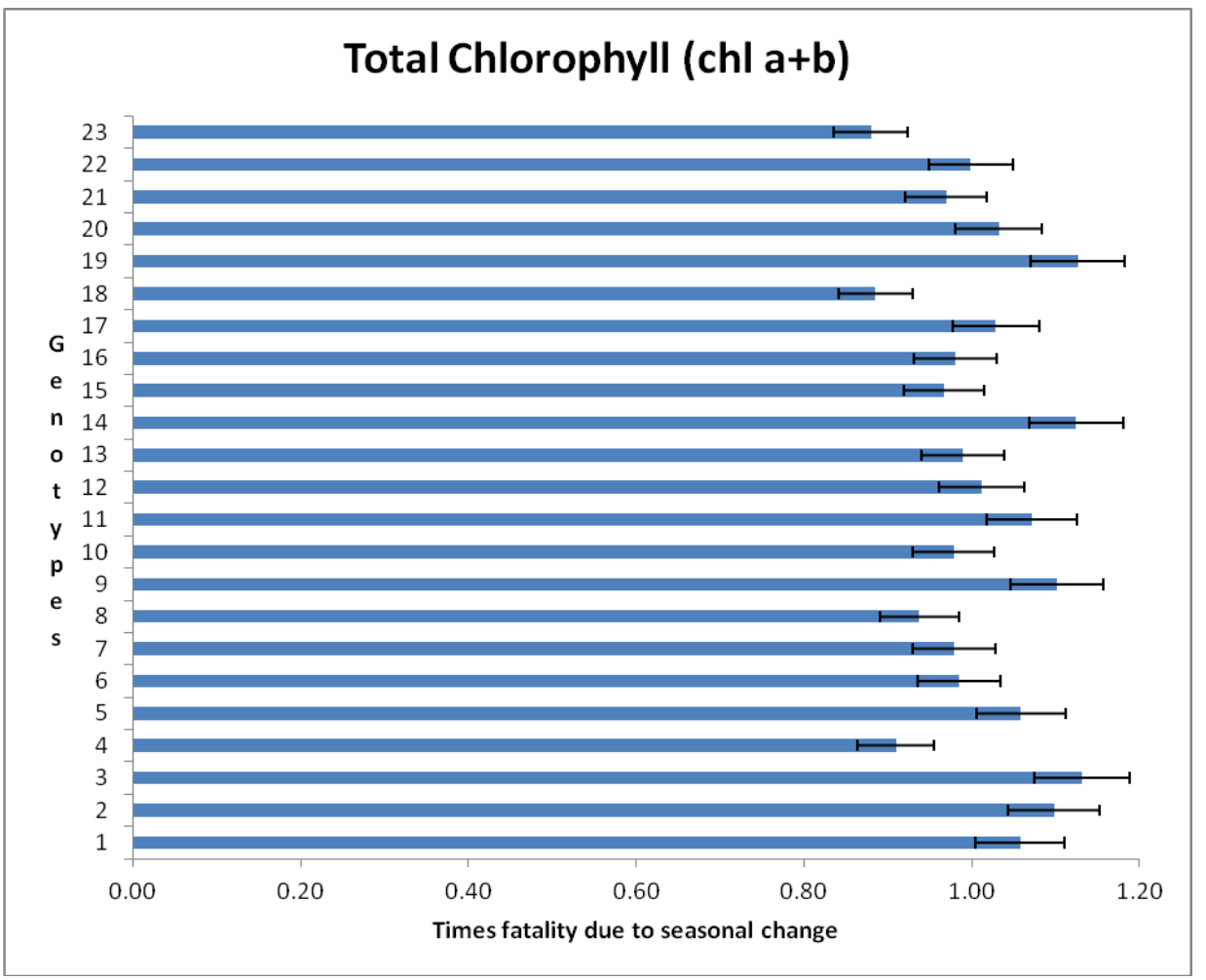

Fig.1c Total chlorophyll $(\mathrm{chl} \mathrm{a}+\mathrm{b})$ fatality due to seasonal changes

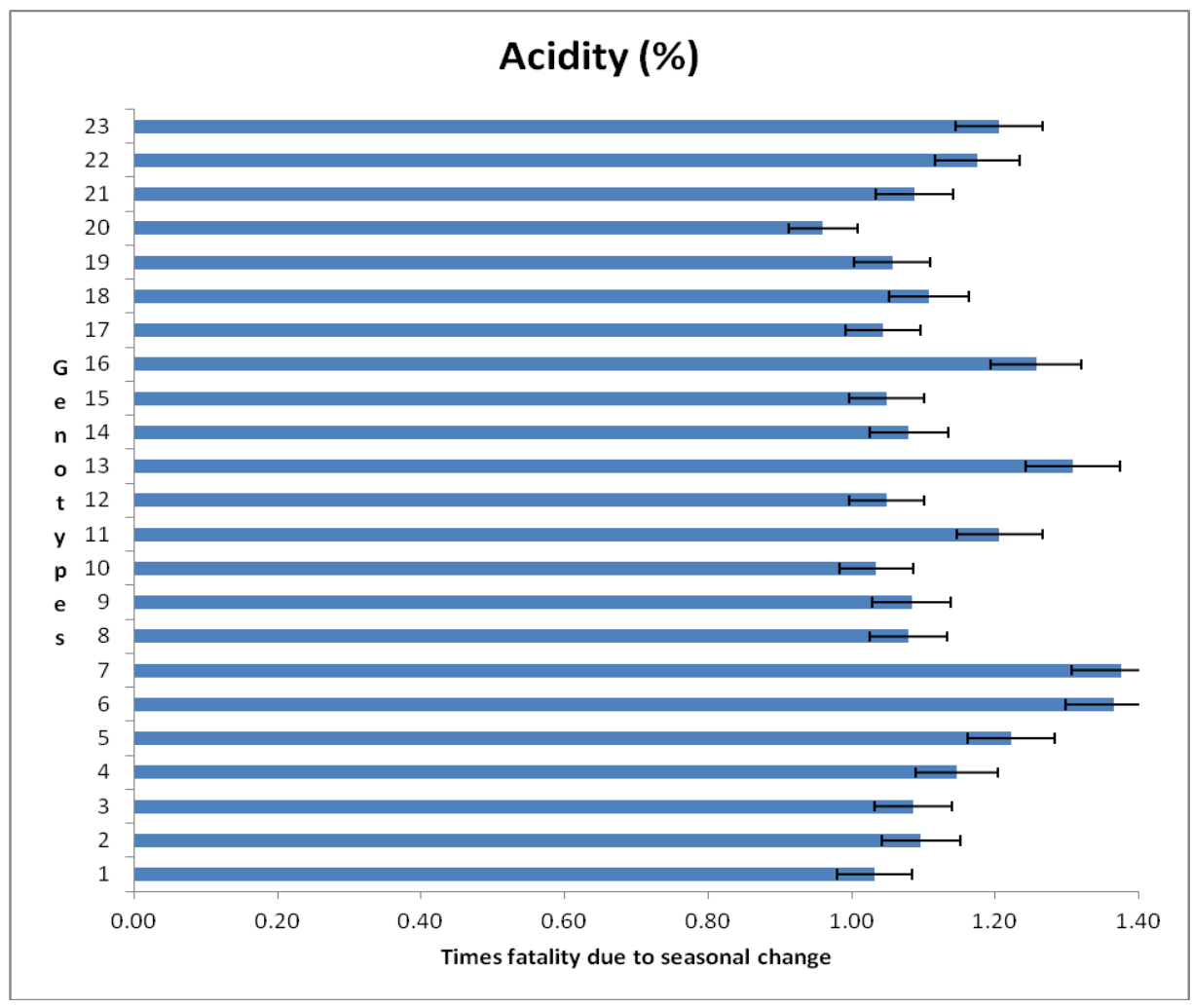


Fig.1d Titrable acidity \% fatality due to seasonal changes

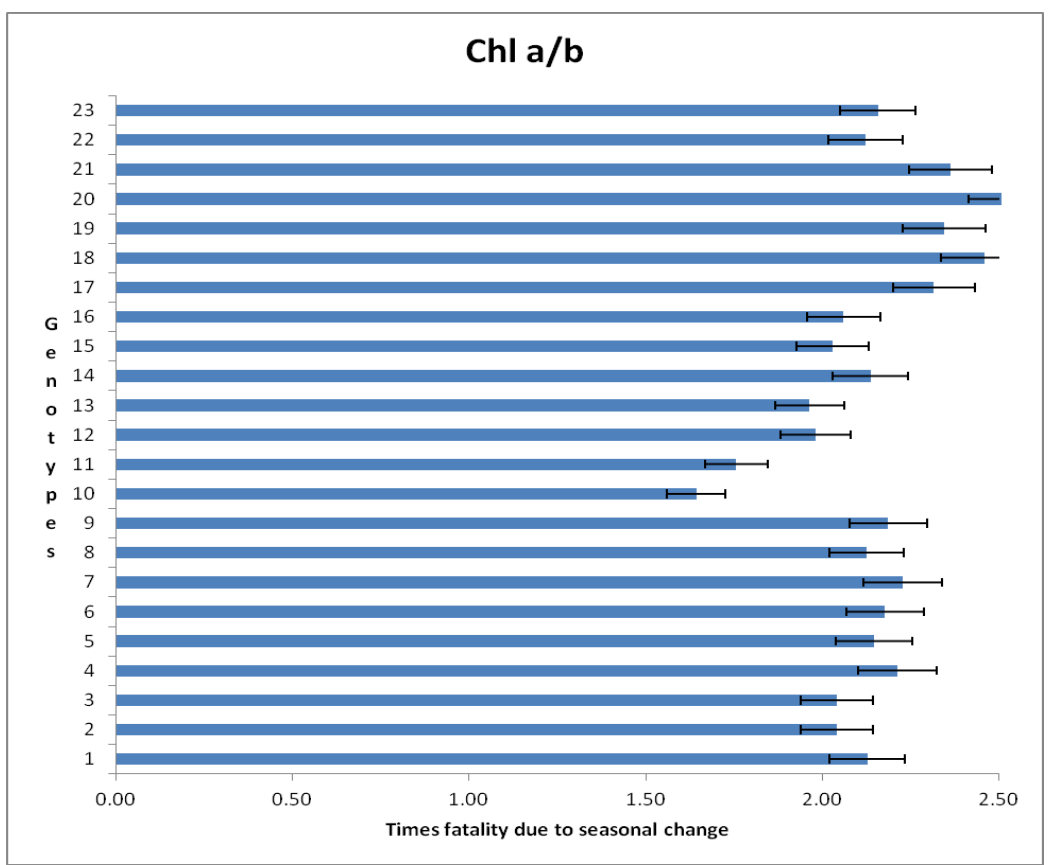

Fig.1e chlorophyll a/b fatality due to seasonal changes

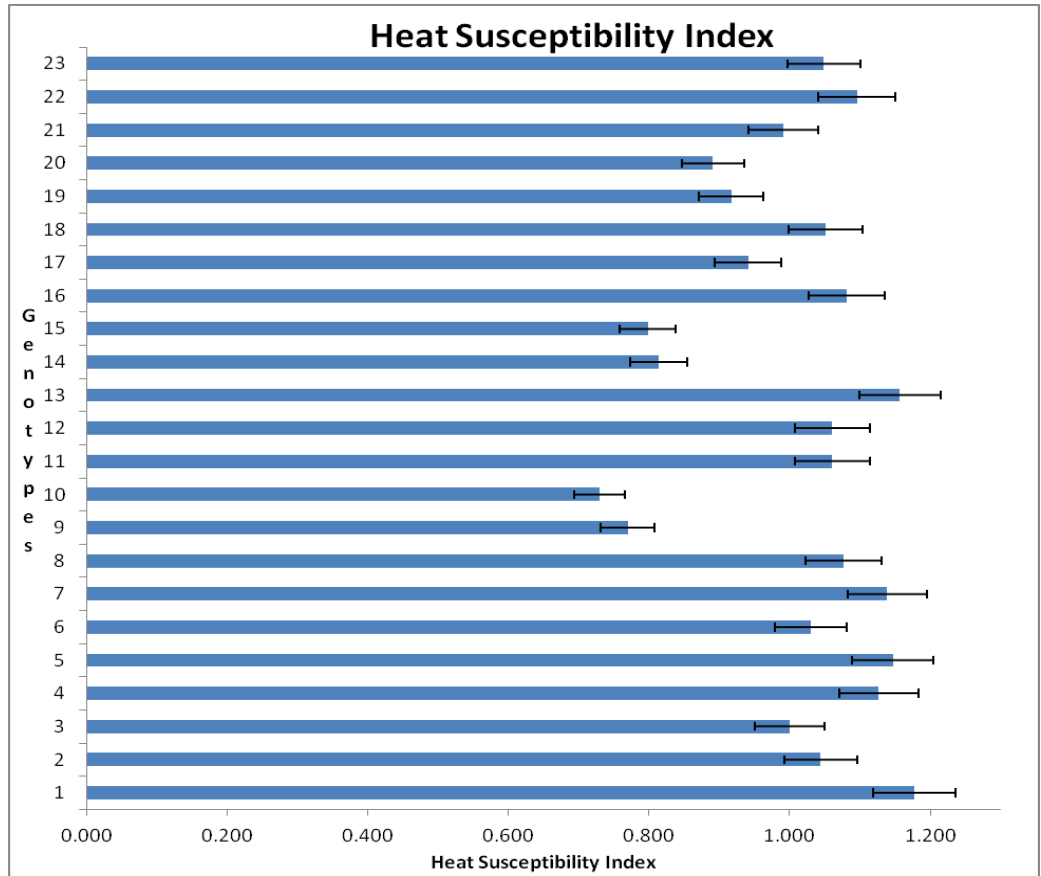

Fig.1f Heat Susceptibility Index fatality due to seasonal changes

1. EC-620386, 2. Pant T-3, 3. EC-605696, 4. EC-620476, 5. EC-620504, 6. EC- 447708, 7. EC-521069, 8. IIHR2202, 9. SEL-18, 10. PS-1, 11. Hisar Arun, 12. Punjab Chhuhara, 13. EC- 650513, 14. EC-538156, 15. EC-538455, 16. EC-560340, 17. 15-SB, 18. EC- 568941, 19. EC-538441, 20. Kashi Amrit, 21. EC-528372, 22. EC-362941, 23. EC-501577 
It sometimes represents a measure of genotypic yield potential under heat stress (Bruckner and Frohberg, 1987) but does not account for differences in yield potential among genotypes (Clarke et al., 1992). Ahmad et al., (2003); Hossain and Teixeira da Silva (2012a) and Hossain et al., (2012d) claimed HSI to be a measure of yield stability. The ideal tomato genotype should be high yielding under any environmental conditions. However, since genetic effects are not independent of environmental effects, most genotypes do not perform satisfactorily in all environments (Carvalho et al., 1983). From the flowering and yield attributes Hisar Lalit (Sel-18) showed higher degree of tolerance, whereas, in terms of HSI Hisar lalit and PS-1 showed moderately tolerant and should be perform better under any environmental conditions.

\section{References}

Abdalla, A. A., and Verkerk, K. 1968. Growth, flowering and fruit set of the tomato at high temperature. Neth. J. Agr. Sci. 16: 71-76.

Ahmad, R., Qadir, S., Ahmad, N., Shah, K.H., 2003. Yield potential and stability of nine wheat varieties under water stress conditions. Int. J. Agric. Biol. 5 (1), 7-9.

Arnon, D.I., 1949. Copper enzymes in isolated chloroplast. Polyphenoloxidase in beta vulgaris. Plant Physiol 24:1-15.

Bruckner, P.L., Frohberg, R.C., 1987. Stress tolerance and adaptation in spring wheat. Crop Sci. 27, 31-36.

Camejo, D.R., Pedro, Angeles M 2005. High temperature photosynthetic activity of two tomato cultivers with different heat susceptivity. J. Plant Physiol 162: 281 289.

Carvalho, F.I.F., Federizzi, L.C., Nodari, R.O., 1983. Comparison among stability models in evaluating genotypes. Rev. Bras. Genét. 6 (4), 667-691.
Clarke, J.M., Depaw, R.M., Townley-Smith, T.F., 1992. Evaluation of methods for quantification of drought tolerance in wheat. Crop Sci. 32, 723-727.

Dinar, M., and Rudich, J. 1985. Effect of heat stress on assimilate partition in tomato. Ann. Bot. 56:239-249.

Eti, S., 1991. Bazý meyve tür veçe pitlerinde deðibik in Vitro testler yardýmýyla çiçektozu canlýlýk ve çimlenme yeteneklerinin belirlenmesi.Cukurova Universitesi, Ziraat Fakultesi Dergisi. 69: 80-91

Fischer, R.A., Maurer, R., 1978. Drought resistance in spring wheat cultivars. I. Grain yield responses. Aust. J. Agric. Res. 29, 897-912

Hossain, A., Teixeira da Silva, J.A., 2012a. Phenology, growth and yield of three wheat (Triticum aestivum L.) varieties as affected by high temperature stress. Not. Sci. Biol. 4 (3), 97-106.

Hossain, A., Teixeira da Silva, J.A., Lozovskaya, M.V., Zvolinsky, V.P., Mukhortov, V.I., 2012d. High temperature combined with drought affect rainfed spring wheat and barley in south-eastern Russia: Yield, relative performance and heat susceptibility index. J. Plant Breeding Crop Sci. 4 (11), 184-196.

Peet, M.M., Willits, D. H., and Gardner, R. 1997. Response of ovule development and postpollen production processes in male-sterile tomatoes to chronic, subacute high temperature stress. J. Experimental Botany. 48 (306): 101111.

Porat, R., Daus A, Weiss B, Cohen L, Fallik E, Droby S 2000. Reduction of postharvest decay in organic citrus fruit by a short hot water brushing treatment. Postharvest boil. Tec. 18(2): 151-157.

Porra, R.J., Klein O, Wright P E 1989. Eur J Biochem. 130:509-516.

Pressman, E., Peet M, Pharr D M 2002. The 
effect of heat stress on tomato pollen characteristics is associated with changes in carbohydrates concentration in developing anthers. Annals of botany 90: $1-6$
Shellie, K.C., Mangan R L 1996. Tolerance of red-fleshed grapefruit to a constant or stepped temperature, forced-air quarantine heat treatment. Postharvest boil. Tec. 7 (1-2): 151-159.

\section{How to cite this article:}

Singh, A.K., R.P. Singh, K. Singh, M.K. Singh, Avanish Kumar Singh and Umesh Singh. 2017. Fatalities due to Seasonal Variation in Tomato Genotypes. Int.J.Curr.Microbiol.App.Sci. 6(9): 2434-2441. doi: https://doi.org/10.20546/ijcmas.2017.609.299 